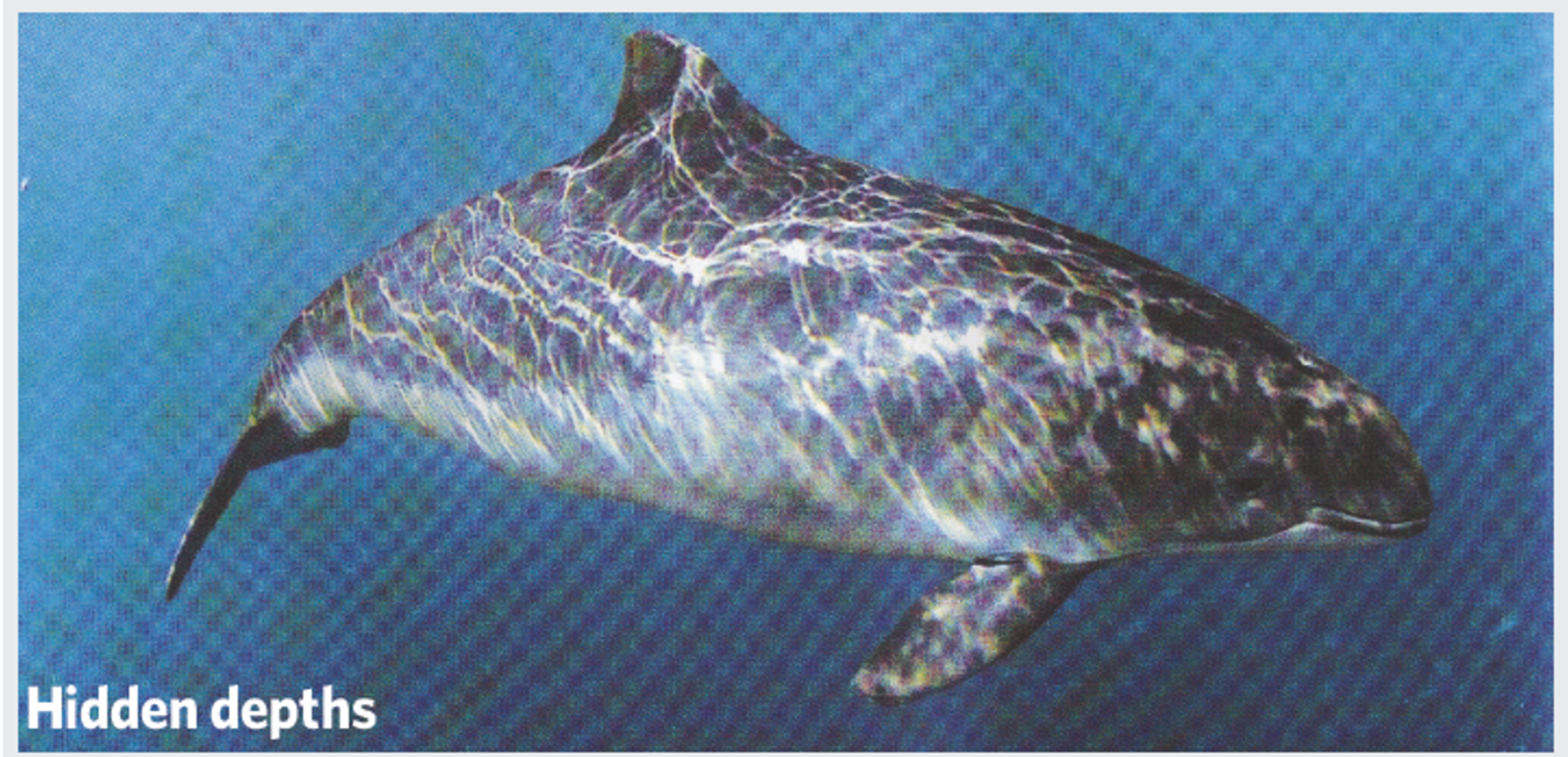

The photographer Bill Curtsinger has completed 33 photographic essays for National Geographic magazine as part of his quest to reveal marine species in their natural settings. The photograph of the harbour porpoise above is from his book Extreme Nature:Images From the World's Edge (White Star, $€ 29.20$ ).

climbed out of, complete with tyre tracks.

Roving Mars is a model of how to draw the public into space exploration. The giant size and excellent sound make the movie especially commanding, but even the TV-resolution DVD that may soon be available would be suitable for showing in schools. A 20-page 'educator guide' can be downloaded from the official website, which includes an excellent 90 -second trailer that samples various parts of the movie.

The film can now be seen at IMAX cinemas across the United States and will be released in other countries later in 2006.

Jay M. Pasachoff is Field memorial professor of astronomy at Williams College, Williamstown, Massachusetts O1267, USA.

\title{
The chamber of wonders
}

\section{From Private to Public: Natural Collections and Muse ums \\ edited by Marco Beretta \\ Science History Publications: 2005. 272 pp. $\$ 39.95$}

\section{Kathie Way}

We have all visited museums of natural history and perhaps been excited, intrigued, inspired — or even thoroughly bored — by the objects on display. But I suspect that we seldom pause to wonder how the contents of these galleries arrived in their mahogany drawer or tabletop vitrine. These essays, edited by Marco Beretta, address and offer answers to this question.

In his excellent preface, Beretta discusses the idea that the emergence of natural history as an independent discipline "was closely connected to the possession and domination of nature, rather than its contemplation". Thus it was the passion for collecting natural-history artefacts from the Renaissance to the end of the eighteenth century that drove the establishment of the discipline. The growth of exploration, the trade routes forged by the East
India Company, and the burgeoning enthusiasm for 'cabinets of curiosity', beginning in the seventeenth century, support this chronology. The 12 expert contributors to this volume provide a wealth of historiographic data drawn from late Antiquity to the nineteenth century, and examine the role of the natural-history collection through time.

Giovanni di Pasquale looks at how the Greeks and Romans documented the past through the accumulation of relics, from the ancient library at Alexandria to the established Roman museums and their collections. The suggestion that collecting relics condemns a still evident culture to the distant past is an interesting one. Susana Gómez López deals with Spanish museum collections from the fifteenth century onwards and concentrates on the link between the scientific thinking of the time and the collections in Seville, a port of entry for commodities, including slaves, from the New World. She uses a number of sixteenth-century personalities, including Spain's King Philip II, to illustrate the collecting ethos of the time and the value of collections in communication. The contemporary importance of access, a vital performance indicator for modern museums, is highlighted.

The Renaissance Wunderkammer, or chamber of wonders, tended to be the private preserve of a rich or royal coterie with the means to indulge their passion for bringing together natural and artistic objects, which were often presented together in ornate cabinets. Alessandro Tosi compares the relatively unscientific Wunderkammer of the German tradition with the great Italian Renaissance collections of Ulisse Aldrovandi, Francesco Calzolari and others, which were almost exclusively devoted to natural history and were an important component of an emerging scientific culture.

Anna Maerker discusses the anatomical collections of La Specola in Florence and the Josephinum in Vienna, and examines the transition of the former from a cabinet of curiosities to a public museum. She also explores how the rejection by both physicians and surgeons of collections of anatomical models, which they dismissed as merely a source of entertainment for the middle dasses, led to a rapprochement of these hitherto rather antagonistic disciplines. Samuel Alberti's article focuses on the concept of ownership of collections, and cites John and William Hunter as private collectors whose anatomical collections became public when they were sold to the University of Glasgow in Scotland; medical students were afforded free access while the public had to pay. Collections made and owned by learned societies formed the basis of today's great regional museums, such as those in Manchester and Sheffield, and Alberti compares the ways in which such regional museums developed.

The paper by Jonathan Simon on eighteenth- 